\title{
Action Observation for Neurorehabilitation in Apraxia
}

\author{
Mariella Pazzaglia ${ }^{1,2 *}$ and Giulia Galli² \\ ${ }^{1}$ Department of Psychology, University of Rome "La Sapienza," Rome, Italy, ${ }^{2}$ IRCCS Fondazione Santa Lucia, Rome, Italy
}

Neurorehabilitation and brain stimulation studies of post-stroke patients suggest that action-observation effects can lead to rapid improvements in the recovery of motor functions and long-term motor cortical reorganization. Apraxia is a clinically important disorder characterized by marked impairment in representing and performing skillful movements [gestures], which limits many daily activities and impedes independent functioning. Recent clinical research has revealed errors of visuo-motor integration in patients with apraxia. This paper presents a rehabilitative perspective focusing on the possibility of action observation as a therapeutic treatment for patients with apraxia. This perspective also outlines impacts on neurorehabilitation and brain repair following the reinforcement of the perceptual-motor coupling. To date, interventions based primarily on action observation in apraxia have not been undertaken.

\section{OPEN ACCESS}

Edited by:

Giorgio Sandrini,

University of Pavia, Italy

Reviewed by:

Marianna Capecci,

Polytechnical University of Marche,

Italy

Marialuisa Gandolfi,

University of Verona, Italy

*Correspondence:

Mariella Pazzaglia

mariella.pazzaglia@uniroma1.it

Specialty section:

This article was submitted to

Neurorehabilitation,

a section of the journal

Frontiers in Neurology

Received: 30 August 2018

Accepted: 11 March 2019

Published: 03 April 2019

Citation:

Pazzaglia M and Galli G (2019) Action

Observation for Neurorehabilitation in Apraxia. Front. Neurol. 10:309. doi: 10.3389/fneur.2019.00309
Keywords: apraxia, action recognition, action execution, mirror activity, neurorehabilitation

\section{INTRODUCTION}

Apraxia encompasses a broad spectrum of higher-order purposeful movement disorders (1) and is most often associated with neurological damage to left-hemisphere (2). The accepted definition of apraxia includes deficits in performing, imitating, and recognizing skilled actions involved in the intentional movements, colloquially referred to as gestures (3). Pathological conditions such as apraxia result from an inability to evince the concept of specific actions (4) or to execute related motor programs (5). Classically, apraxia is diagnosed when a patient presents with an inability to execute gestures in response to verbal commands or imitate with different effectors (mouth, hand, or foot) (4), including movements involving the non-paretic limb ipsilateral to the lesion[s]. Although apraxia primarily affects motor activities, studies report that higher impairment levels may be related to visuo-motor integration (6). Recent evidence supports the notion that apraxia influences skilled acts in the environment, interferes with independent functioning, impedes daily activities, and affects the performance of routine self-care $(7,8)$; that is, persons may have difficulty brushing their teeth (9), eating (7), preparing food (10), and getting dressed (11). As a consequence, patients with apraxia can develop severe anxiety and reductions in the spontaneous use of social gestures (12), leading to isolation and depression (13) and consequent delays in returning to work (14).

Almost 50\% of patients with left-hemispheric stroke (15) and 35\% of patients with Alzheimer's disease and corticobasal degeneration (16-18) develop apraxia that persists after illness onset and affects functional abilities. Research to aid in the development and optimization of apraxia neurorehabilitation is crucial. Several approaches for the treatment of apraxia deficits are currently in practice [for a review see $(19,20)$ ], including verbal $(21)$ or pictorial $(22)$ facilitation and the use of physical cues based on repetitive behavioral-training programs with gesture-production exercises. The errorless completion method represents another recent approach (23). Autonomy in 
activities of daily living tends to be underestimated (24), and rehabilitation studies remain limited due to the nature of disturbances to automatic/voluntary dissociations (i.e., an ability to execute actions only in natural settings). To date, no rehabilitation treatment or therapeutic possibilities based primary on action observation has been studied in apraxia.

\section{THE VALUE OF ACTION OBSERVATION IN TREATING APRAXIA}

Language disorders among patients with apraxia who suffer from concomitant aphasia suggest that defects in gesture imitation, rather than gestures in response to verbal commands, are more sensitive indicators of apraxia (25). Goldenberg has proposed that imitation apraxia could be primarily considered a deficit of perceptual analysis (26). Evidence from several studies indicates that perceptual and motor codes are closely associated (27, 28 ) and that patients with apraxia may be defective both in performing motor acts and in the perceptual code necessary to represent the appropriate gesture. Sunderland and Sluman have shown, for example, that problems orienting a spoon in a beanspooning task suggest an inability to remember the correct action and to judge the correctness of the perceived action (29).

Although apraxia is commonly considered a motor impairment, deficits in intact gestural perception are not uncommon, occurring in 33\% of one sample (30). Such patients, who exhibit deficits in the execution of actions, also commit errors when judging between correctly and incorrectly performed acts (30-32), understanding the meaning of pantomimes $(33,34)$, discriminating among action-related sounds $(35,36)$, matching photographs of gestures (26), engaging visuo-motor temporal integration (6), and predicting incoming observed movements $(37,38)$.

Movement-execution effects in apraxia thus are not purely motor processes and visual representations of given actions may influence the actions' execution by visuo-motor transfer (39). The integrity of gesture representations has important implications for rehabilitation strategies (40). The spatial and temporal use of a body part for the planning of a tool-related action and the imitation of others' actions involve an inherent perceptual component, which can be disturbed following apraxia onset. As a result, modern assessments of apraxia include evaluations of gesture understanding $(32,41)$.

\section{VISUAL-MOTOR STRATEGIES IN THE REHABILITATION OF PATIENTS WITH LIMB APRAXIA}

The notion of common representations for both executed and observed actions is of considerable interest in the applied field of stroke neurorehabilitation $(42,43)$. Despite the use of stateof-the-art apraxia-evaluation batteries (44) to explore perceptual deficits in the understanding of actions in patients with apraxia, few studies have proposed new rehabilitation programs that include elements of both observation and execution of actions.
Smania et al.'s (45) clinical examinations of 43 left braindamaged patients with apraxia revealed defective performances in gesture execution and imitation, as well as in the recognition and identification of transitive and intransitive gestures. For their study, approximately half of the patients received training in ecological action production and comprehension; the other half underwent conventional language rehabilitation for the same number of treatment hours. The training, which combined the observation and execution of observed actions, consisted of three progressive phases, each characterized by increasing degrees of difficulty, obtained by phased reductions of facilitation cues as performance improved. After $\sim 30$ sessions, therapists recorded significant improvements: approximately $50 \%$ improvement in the ADL scale and an average of $40 \%$ in the praxis test (22). When only considering apraxia patients with cortical lesions primarily in the fronto-parietal network, the improvement was even greater (45). No significant performance changes were observed in the outcome measures of control patients who did not undergo specific programs of gesture production/observation exercises. Interestingly, authors reported a significant improvement in gesture recognition performance after the apraxia treatment, and a correlation was found between gesture comprehension tests and the ADL questionnaire (ADL-gesture comprehension: $R=0.37, p=0.034)(22)$. These results suggest that the positive effects of this rehabilitative approach in apraxia require parity in the treatment of both the motor and the perceptual aspects of action processing (45). Of note, beneficial effects persisted for at least 2 months and extended to the daily living activities even of untreated actions, helping patients attain functional independence from their caregivers (22).

Goldenberg and Hagmann (9) developed a particularly successful restorative method in which training comprised two different methods. The first aimed at helping patients to learn and correctly execute complete activities, with therapists providing different support at all clinical steps (e.g., by demonstrating gesture execution and asking patients to imitate them), and reducing the support only when patients were able to perform these steps on their own. The second aimed at directing patients' attention to the functional meaning of objects' individual features and details, critical for various actions. This two-step procedure ensured a double reinforcement of the action's perceptualmotor code: the first online within the simultaneity of the demonstration and the second off-line as a delayed imitation. The combination of these two methods led to significant improvements in trained ADL, but virtually no generalization of training effects was observed between trained and non-trained activities. The therapy's success was preserved among those patients who performed the activities at home but not among those who did not. In a subsequent study (46), the authors developed a slightly different variant to previous approaches in which patients carried out entire activities with a minimum of errors. In this approach, the functional commonalities between different objects were emphasized by providing verbal instructions and visual and gestural support. Effects of these treatments lasted up to 3 months after the treatment ended.

Compensatory treatment indicate that the patients showed large improvements in ADL functioning after rehabilitative 
programs aiming at teaching visual strategies to overcome the apraxic impairments during execution of everyday activities (47). Patients were taught strategies to compensate internally (e.g., self-verbalization or imagination) or externally (e.g., observation of pictorial cues) the distinct phases of a complex action, while performing the daily activities (47-50).

All described interventions included elements of visuo-motor integration and seemed to indicate that motor and visual relearning in these patients was inextricably intertwined (see Table 1).

Perceptual approach has been successfully applied to a different rehabilitative intervention showing how action observation has a positive effect on the performance of a specific motor skill [for a review see $(41,52,53)$ ]. Patients watch a specific motor act presented in a video clip or in a real demonstration, and simultaneously (or thereafter) performed the same action. A match (or mismatch) between visual signals and the gesture performed drive re-learning about how the limb should move in order to perform the motor act accurately (see Figure 1 for a hypothetical model on apraxia). Correctly reproducing temporal $(56,57)$, spatial (58), and body coding (59) helps characterize movements, facilitate the motor patterns that patients have to execute, and stimulate a rapid online correction of movement $(58,60,61)$. Observation combined with physical practice in a congruent mode leads to increased motor cortex excitability, and synaptic and cortical map plasticity strengthens the memory trace of the motor act (62). Differently, rehabilitative training based on physical practice alone (300-1,000 daily repetitions) elicits only minimal neural reorganization (63). This combined visual-motor therapy has been shown to improve motor performance in patients that suffered a chronic stroke (64-86), patients with Parkinson's disease (87-92), children with cerebral palsy (93-97) and elderly individuals with reduced cognitive abilities (98). Electrophysiological studies have also reported positive effects of action observation on the recovery of motor functions after acute and chronic stroke $(71,99)$. This non-invasive, inexpensive, user-friendly approach works more quickly on biological effectors (mouth, limbs, and trunk), promoting better and faster recovery.

\section{A NEURAL SUBSTRATE FOR ACTION OBSERVATION AND EXECUTION IN APRAXIA REHABILITATION}

The inextricable link between action perception and execution was first posited in the ideomotor theory, which has been validated through delineation of the brain network, known as the mirror neuron system (MNS). Inspired by single-cell ("mirror neuron”) recordings in monkeys $(100,101)$, many neuroimaging and neurophysiological studies have suggested that the adult human brain is equipped with neural systems and mechanisms that represent both the visual perception and execution of actions in a common format (102). Action deficits among the patients with apraxia may be described at multiple levels. While these levels partially overlap, four levels of hierarchical modeling at which an MNS mechanism can support an observed action $(42,103)$ are as follows:

(i) kinematic: Patients with apraxia frequently present with abnormalities in kinematic movements in the form of motor patterns that are slower, shorter, and less vertical than those of individuals without apraxia (104);

(ii) motor: Limb apraxia interferes with the selection and control of the hand-muscle activity (105). Moreover, it interferes with the formation of appropriate hand configurations for using objects (106);

(iii) goal: Understanding the immediate purpose of an action is impeded; for example, patients with apraxia are impaired access to mental representation of tool use (33);

(iv) intention: Patients present with an altered ability to monitor the early planning phases of their own actions (107).

The cortical areas have been shown to contain mirror neurons that are often described as a part of an integrated sensorimotor information system underpinned by neural activity in the frontal (103), parietal (108), and superior temporal sulcus areas. This system is called the action observation network (AON) (109). In humans, these cortical regions mediate the observation of actions that form a part of the observer's motor repertoire (41). They also contribute to the imitation (110) and comprehension (111) of these movements, and are involved in skill acquisition (112). Lesion symptom mapping studies have reported gestural deficits in patients with apraxia, which are most frequently apparent following lesions in the inferior frontal lobe $(30,113-$ 116), and in supramarginal and angular gyrus (37, 113, 115, 117) of the left hemisphere. However, apraxia has also been observed in patients with damage in posterior middle temporal lobe, anterior temporal lobe $(37,113,115,117)$, occipital, and subcortical regions $(6,118,119)$. Despite the damaged neural substrate was not constant across all the studies, it includes the areas that are considered crucial for the AON. Undoubtedly, the mirror neurons just provide a part of the complex information for achieving action comprehension while action recognition and production occur simultaneously by accessing the same neural representations. However, as posited by the influential cognitive neuropsychological models of apraxia $(120,121)$ and demonstrated by various clinical studies (121-124), the range of possible dissociations between action execution and action understanding that can occur in patients with apraxia is quite multifaceted and cannot be explained by a mere action mirroring mechanism nor by a single lesion locus. Impairments in the visual recognition of action paralleled deficits in performing these actions could depend on both common and distinct neural localization, most of which could be external to mirror regions. Failures in imitating or in recognizing gestures may occur because of damage at any level in the process between perceiving (input lexicon) and performing (output lexicon) an action $(120,121)$. Indeed, some apraxic patients show deficits in the recognition/discrimination of the gestures, some do not [for a review (125)]. Theoretical and empirical studies suggest that complementary routes to action understanding taking place on the dorso-dorsal and ventro-dorsal stream $(126,127)$. Lesion in ventral-dorsal stream may impede the top-down activation 


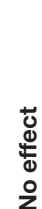

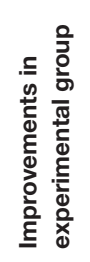

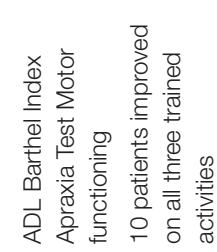

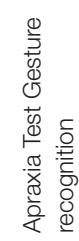

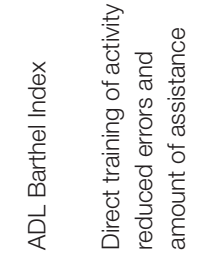

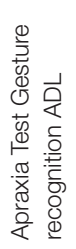

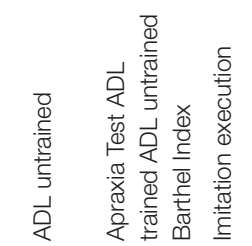

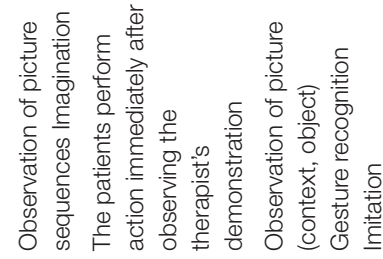

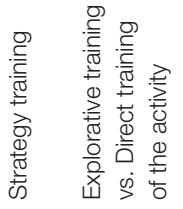

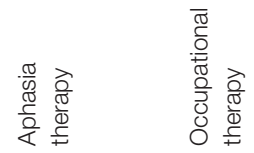

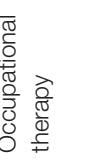

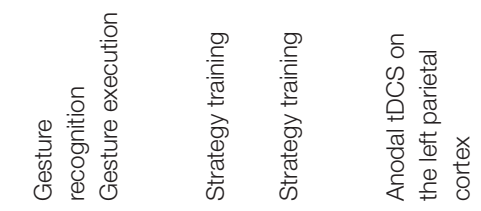

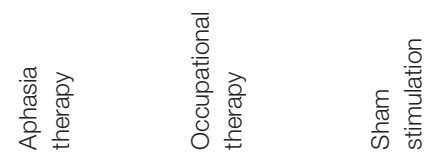

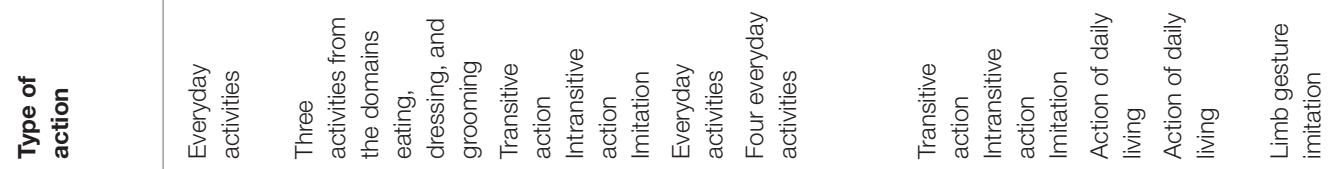

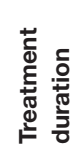

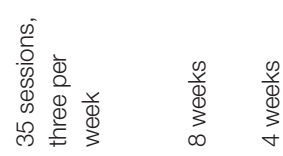

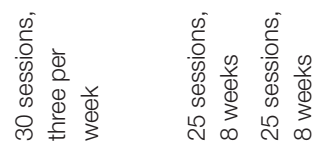

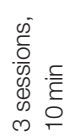

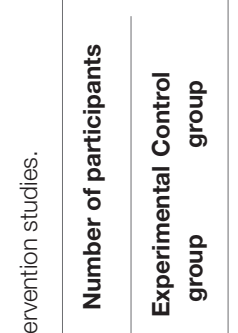

$\stackrel{M}{\infty}$

$\circ$

ชู 0

$\stackrel{\infty}{\sim}$

吕

崖

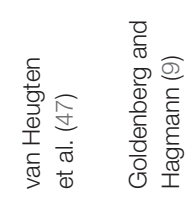

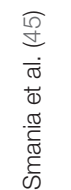

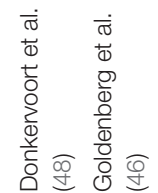

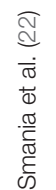

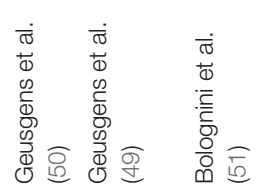



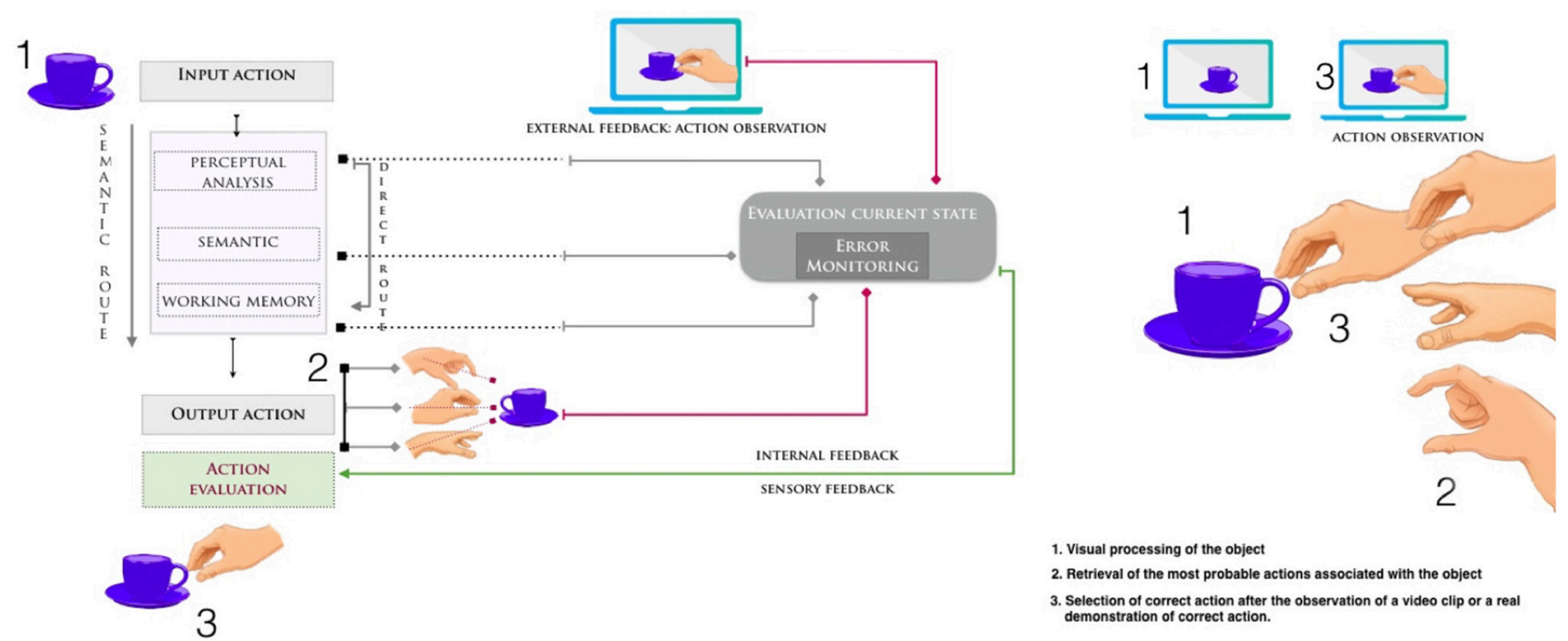

FIGURE 1 | Hypothetical model for performing and recognizing a transitive action [adapted from (54) and (55)]. Failures in performing or recognizing gestures may occur because of damage at any stage in the directional flow between perceiving (input) and performing (output) the action. The observation of a video clip or a real demonstration of action can have a positive effect on the selection and retrieval of the correct movement. In figure the example of grasping a cup of coffee. After the correct visual identification of the object as a cup, patients with apraxia have a difficult retrieval of the correct action associated with that object. When an incorrect movement is performed, a discrepancy occurs between the (correct) action observed on the model and the perception of own (incorrect) performed gesture. Combining motor training and action observation may enhance the relearning of daily actions and strengthen the visuo-motor coupling.

of motor engrams. It may produce disturbances in the online selection and integration of distinctive and relevant motor acts that ensure a high recognizability of the gesture (117). This can be responsible for the disordered motor planning, imitation, and motor-memory recall of gesture movements found in patients with apraxia $(126,127)$. As has been briefly shown, many questions remain, and there may be more than one mechanism leading to apraxia disturb. Given the complexity of the impairment and the separate neural substrates that are typically affected in apraxia, treatments related to action observation to support action execution or relearning of gestures of daily living, can be planned.

\section{NEUROREHABILITATION AND BRAIN REPAIR AFTER APRAXIA}

The behavioral success of rehabilitation methods based on the principle of action observation should promote reorganization by adaptive plasticity at the neural level $(128,129)$. Functional reorganization clearly depends on the residual neural integrity of efferent (motor) and afferent (sensory) information, which leads to improved treatment outcomes among some apraxia patients but not for others. In this perspective, we considered three possible sources of informational content for how neurorehabilitation and brain repair after apraxia works: injury site, elapsed time after apraxia onset, and lesion size.

The first factor to consider is the location of the infarct, which can ultimately determine the outcome of rehabilitation treatment. Whereas, lesions of the frontal and parietal cortices in the left hemisphere have been shown to primarily disrupt gesture production in patients with apraxia (2), no clear correlation has been found between lesion location and impairment in visual gesture representation. Apraxic patients with cortical lesions-but not those with subcortical lesionscannot comprehend the meaning of gestures (130). In rare cases, a lesion in the left occipito-temporal cortex may also critically hamper the ability to recognize gestures in patients with apraxia $(120,131)$. Patients with parietal lesions have also been reported to exhibit significant impairments in executing gestures but only slight impairments in understanding those performed by others (132). The neural specificity of this disturbed typology may explain why certain patients with apraxia are able to comprehend the meaning of gestures despite being unable to perform them themselves. Accordingly, single-case and group studies report dissociations between action execution and representation and the underpinning damaged neural substrate (121-124). Efficiency and speed of the therapeutic means of action observation depend partly on the different roles that intact and damaged brain regions play in both action production and recognition $(125,133)$. Neural damage to a functional system can be partial, and studies in monkeys seem to suggest that the frontal and parietal cortices are neurally equipped for such divisions of labor (134).

Several studies have documented that neurorehabilitation techniques involving observation strategies among braindamaged patients induce long-lasting neural changes in the motor cortex, potentiating activity in the affected areas. In brain-damaged patients, TMS studies have found direct evidence of increased motor-cortex excitability (84), and synaptic and cortical map plasticity have been documented using fMRI (75). 
TMS studies have also indicated that action observation alone is able to drive reorganization in the primary motor cortex, strengthening the motor memory of observed actions among young (135) and elderly subjects (mean ages: 34 and 65 years, respectively) (98) and among chronically brain-damaged patients (84). Additionally, a study reported positive effects on gesture imitation of anodal transcranial direct current stimulation (tDCS) on the left parietal compared to sham tDCS, supporting the view that apraxia disorders in Parkinson (136) and in brain left damaged patients (51) can be improved by stimulating distinct structures.

A second factor to consider is the temporal stage of the illness. The neural substrates of action production and comprehension could be associated with different physiological mechanisms at different temporal stages of apraxia. Frontal and parietal areas may become temporarily inactive because of cerebral edema and intracranial hypertension, hemodynamic signs of ischemic penumbra, or local inflammatory effects in acute but not chronic stages of apraxia (137). Different studies report that during early periods (including an acute four-week, post-onset phase), impaired gesture recognition may be associated with left frontallobe and basal-ganglia lesions (138), whereas in the chronic stages of the illness, these deficits can be associated with left-parietal lesions $(32,37)$.

In practice, transitory effects such as the inability to mimic actions from visual cues are often observed in apraxia's early stages. If so, an observation intervention in early therapy may be inefficacy.

During later apraxia stages, a close overlap of the networks underlying observation and execution, as indicated by advanced neuroimaging and the lesion locations studies in patients, are helpful in identifying patient in which observative approach is potentially useful. Observation therapy associated with adaptive neurophysiological and neurometabolic changes can be conducted even several years after stroke onset. A session of 4 weeks of active, 18 days-cycle visual/motor training has been found to significantly enhance motor function, with increases in the activity of specific motor areas that possess mirror properties (75). Massed, high-frequency rehabilitative training (300-1,000 daily repetitions) is needed to elicit minimal neural reorganization (63). These increases in cortical activity during both action observation and execution also tend to be present in the hemispheres $(139,140)$ close to and far from the lesion site.

A third possible factor to consider is that the failure to link perceptual and motor representations in apraxia treatment may be an effect of infarct size; larger lesions are more likely to include front parietal injury and may not benefit from observation treatment. Indeed, improvements in imitation (reproduction off-line of the observed gesture) in patients with apraxia are influenced by the size of the parietal lesion (51): the larger the left parietal damage, the smaller the tDCS treatment-related improvement. When a functional system is completely damaged, however, recovery is achieved largely by process of substitution and may depend on the implicit engagement of neural systems to take over the functions of the damaged areas (141).

Whereas, some systems may constitute the sites of gesture performance, others may reduce the impact of deficits (142) by stimulating coupled visual knowledge mechanisms (98). The integrity of both the frontal and parietal cortices might be crucial for re-learning as a result of motor mirroring. Nonetheless, noninjured cortical areas could also trigger additional, independent internal mechanisms that support but are not necessary for guiding the motor system to match vision with motor routines $(143,144)$. Studies on the neural representations of motor skills based on observations of the motor cortex of macaque monkeys (145) and humans (146) provide empirical support for such an alternative system. These studies suggest that congruent activity during action execution/observation occurs even outside the canonical "mirror area," representing a potential general property of the motor system. Targeting interventions on the basis of specific brain structures intact and damaged that could mediate the effects of training is an important future challenge in cognitive neurorehabilitation.

\section{CONCLUSION}

While research on the relationship between observed and executed actions in apraxia neurorehabilitation has a short history, it has already provided insights about the positive effect of a visual-motor training. The observation of actions through a process of visual retrieval may help in the selection of the most probable action, providing a powerful tool for overcoming intentional motor-gestural difficulties (55). Moreover, tailored interventions based on individual's ability to acquire new (or relearn old) motor-memory traces through multisensory [i.e., auditory $(35,147)$, olfactory $(148,149)$, and tactile (150155)] feedback may be the most promising approach for a normal temporal integration action (156, 157). Multisensory stimulation can activate multiple cortical brain structures, inducing cortical reorganization and modulating motor cortical excitability for the stimulated afferents $(158,159)$. Results are encouraging, but it is important to emphasize that this hypothesis does not imply that all deficits in apraxia can be treated by action observation therapy. Rather, we believe that action observation might be a therapeutic option for improving praxis function among certain specific typologies of patients.

\section{AUTHOR CONTRIBUTIONS}

MP: study concept and design, manuscript development, and writing. GG: contributed to the writing of the manuscript.

\section{FUNDING}

This work was supported by the Italian Ministry of Health (RF-2018-12365682 to MP). 


\section{REFERENCES}

1. Leiguarda RC, Marsden CD. Limb apraxias: higher-order disorders of sensorimotor integration. Brain. (2000) $123(\mathrm{Pt} \quad 5): 860-79$. doi: 10.1093/brain/123.5.860

2. Haaland KY, Harrington DL, Knight RT. Neural representations of skilled movement. Brain. (2000) 123(Pt 11):2306-13. doi: 10.1093/brain/123.11.2306

3. Rothi LJ, Heilman KM. Acquisition and retention of gestures by apraxic patients. Brain Cogn. (1984) 3:426-37. doi: 10.1016/0278-2626(84)90032-0

4. Petreska B, Adriani M, Blanke O, Billard AG. Apraxia: a review. Prog Brain Res. (2007) 164:61-83. doi: 10.1016/S0079-6123(07)64004-7

5. Wheaton LA, Hallett M. Ideomotor apraxia: a review. J Neurol Sci. (2007) 260:1-10. doi: 10.1016/j.jns.2007.04.014

6. Nobusako S, Ishibashi R, Takamura Y, Oda E, Tanigashira Y, Kouno M, et al. Distortion of visuo-motor temporal integration in apraxia: evidence from delayed visual feedback detection tasks and voxel-based lesion-symptom mapping. Front Neurol. (2018) 9:709. doi: 10.3389/fneur.2018.00709

7. Foundas AL, Macauley BL, Raymer AM, Maher LM, Heilman KM, Gonzalez Rothi LJ. Ecological implications of limb apraxia: evidence from mealtime behavior. J Int Neuropsychol Soc. (1995) 1:62-6. doi: 10.1017/S1355617700000114

8. Hanna-Pladdy B, Heilman KM, Foundas AL. Ecological implications of ideomotor apraxia: evidence from physical activities of daily living. Neurology. (2003) 60:487-90. doi: 10.1212/WNL.60.3.487

9. Goldenberg G, Hagmann J. Therapy of activities of daily living in patients with apraxia. Neuropsychol Rehabil. (1998) 8:123-41. doi: 10.1080/713755559

10. van Heugten CM, Dekker J, Deelman BG, Stehmann-Saris JC, Kinebanian A. Rehabilitation of stroke patients with apraxia: the role of additional cognitive and motor impairments. Disabil Rehabil. (2000) 22:547-54. doi: 10.1080/096382800416797

11. Sunderland A, Walker CM, Walker MF. Action errors and dressing disability after stroke: an ecological approach to neuropsychological assessment and intervention. Neuropsychol Rehabil. (2006) 16:666-83. doi: 10.1080/09602010500204385

12. Borod JC, Fitzpatrick PM, Helm-Estabrooks N, Goodglass H. The relationship between limb apraxia and the spontaneous use of communicative gesture in aphasia. Brain Cogn. (1989) 10:121-31. doi: 10.1016/0278-2626(89)90079-1

13. Tabaki NE, Vikelis M, Besmertis L, Vemmos K, Stathis P, Mitsikostas DD. Apraxia related with subcortical lesions due to cerebrovascular disease. Acta Neurol Scand. (2010) 122:9-14. doi: 10.1111/j.1600-0404.2009.01224.x

14. Saeki S, Ogata H, Okubo T, Takahashi K, Hoshuyama T. Factors influencing return to work after stroke in Japan. Stroke. (1993) 24:1182-5. doi: 10.1161/01.STR.24.8.1182

15. Zwinkels A, Geusgens C, van de Sande P, Van Heugten C. Assessment of apraxia: inter-rater reliability of a new apraxia test, association between apraxia and other cognitive deficits and prevalence of apraxia in a rehabilitation setting. Clin Rehabil. (2004) 18:819-27. doi: 10.1191/0269215504cr816oa

16. Hodges JR, Bozeat S, Lambon Ralph MA, Patterson K, Spatt J. The role of conceptual knowledge in object use evidence from semantic dementia. Brain. (2000) 123:1913-25. doi: 10.1093/brain/123.9.1913

17. Holl AK, Ille R, Wilkinson L, Otti DV, Hödl E, Herranhof B, et al. Impaired ideomotor limb apraxia in cortical and subcortical dementia: a comparison of Alzheimer's and Huntington's disease. Neurodegener Dis. (2011) 8:208-15. doi: 10.1159/000322230

18. Nelissen N, Pazzaglia M, Vandenbulcke M, Sunaert S, Fannes K, Dupont P, et al. Gesture discrimination in primary progressive aphasia: the intersection between gesture and language processing pathways. J Neurosci. (2010) 30:6334-41. doi: 10.1523/JNEUROSCI.0321-10.2010

19. Cantagallo A, Maini M, Rumiati RI. The cognitive rehabilitation of limb apraxia in patients with stroke. Neuropsychol Rehabil. (2012) 22:473-88. doi: 10.1080/09602011.2012.658317

20. Worthington A. Treatments and technologies in the rehabilitation of apraxia and action disorganisation syndrome: a review. Neurorehabilitation. (2016) 39:163-74. doi: 10.3233/NRE-161348
21. French B, Thomas LH, Coupe J, McMahon NE, Connell L, Harrison $\mathrm{J}$, et al. Repetitive task training for improving functional ability after stroke. Cochrane Database Syst Rev. (2007) 11:CD006073. doi: 10.1002/14651858.CD006073.pub2

22. Smania N, Aglioti SM, Girardi F, Tinazzi M, Fiaschi A, Cosentino $A$, et al. Rehabilitation of limb apraxia improves daily life activities in patients with stroke. Neurology. (2006) 67:2050-2. doi: 10.1212/01.wnl.0000247279.63483.1f

23. Buxbaum LJ, Haaland KY, Hallett M, Wheaton L, Heilman KM, Rodriguez A, et al. Treatment of limb apraxia: moving forward to improved action. Am J Phys Med Rehabil. (2008) 87:149-61. doi: 10.1097/PHM.0b013e31815e6727

24. Etcharry-Bouyx F, Le Gall D, Jarry C, Osiurak F. Gestural apraxia. Rev Neurol. (2017) 173:430-9. doi: 10.1016/j.neurol.2017.07.005

25. Wang L, Goodglass H. Pantomime, praxis, and aphasia. Brain Lang. (1992) 42:402-18. doi: 10.1016/0093-934X(92)90076-Q

26. Goldenberg G. Matching and imitation of hand and finger postures in patients with damage in the left or right hemispheres. Neuropsychologia. (1999) 37:559-66. doi: 10.1016/S0028-3932(98)00111-0

27. Hommel B, Musseler J, Aschersleben G, Prinz W. The Theory of Event Coding (TEC): a framework for perception and action planning. Behav Brain Sci. (2001) 24:849-78. doi: 10.1017/S0140525X01000103

28. Schutz-Bosbach S, Prinz W. Perceptual resonance: action-induced modulation of perception. Trends Cogn Sci. (2007) 11:349-55. doi: 10.1016/j.tics.2007.06.005

29. Sunderland A, Sluman SM. Ideomotor apraxia, visuomotor control and the explicit representation of posture. Neuropsychologia. (2000) 38:923-34. doi: 10.1016/S0028-3932(00)00021-X

30. Pazzaglia M, Smania N, Corato E, Aglioti SM. Neural underpinnings of gesture discrimination in patients with limb apraxia. J Neurosci. (2008) 28:3030-41. doi: 10.1523/JNEUROSCI.5748-07.2008

31. Heilman KM, Rothi LJ, Valenstein E. Two forms of ideomotor apraxia. Neurology. (1982) 32:342-6. doi: 10.1212/WNL.32.4.342

32. Kalenine S, Buxbaum LJ, Coslett HB. Critical brain regions for action recognition: lesion symptom mapping in left hemisphere stroke. Brain. (2010) 133:3269-80. doi: 10.1093/brain/awq210

33. Rothi LJ, Heilman KM, Watson RT. Pantomime comprehension and ideomotor apraxia. J Neurol Neurosurg Psychiatry. (1985) 48:207-10. doi: 10.1136/jnnp.48.3.207

34. Weiss PH, Rahbari NN, Hesse MD, Fink GR. Deficient sequencing of pantomimes in apraxia. Neurology. (2008) 70:834-40. doi: 10.1212/01.wnl.0000297513.78593.dc

35. Pazzaglia M, Pizzamiglio L, Pes E, Aglioti SM. The sound of actions in apraxia. Curr Biol. (2008) 18:1766-72. doi: 10.1016/j.cub.2008.09.061

36. Mutha PK, Stapp LH, Sainburg RL, Haaland KY. Motor adaptation deficits in ideomotor apraxia. J Int Neuropsychol Soc. (2017) 23:139-49. doi: 10.1017/S135561771600120X

37. Fontana AP, Kilner JM, Rodrigues EC, Joffily M, Nighoghossian N, Vargas $\mathrm{CD}$, et al. Role of the parietal cortex in predicting incoming actions. NeuroImage. (2012) 59:556-64. doi: 10.1016/j.neuroimage.2011.07.046

38. Pazzaglia M. Does what you hear predict what you will do and say? Behav Brain Sci. (2013) 36:370-1. doi: 10.1017/S0140525X12002804

39. Pazzaglia M. Impact commentaries. Action discrimination: impact of apraxia. J Neurol Neurosurg Psychiatry. (2013) 84:477-8. doi: 10.1136/jnnp-2012-304817

40. Buxbaum LJ, Randerath J. Limb apraxia and the left parietal lobe. Handb Clin Neurol. (2018) 151:349-63. doi: 10.1016/B978-0-444-63622-5.00017-6

41. Pazzaglia M, Galli G. Translating novel findings of perceptual-motor codes into the neuro-rehabilitation of movement disorders. Front Behav Neurosci. 9:222. doi: 10.3389/fnbeh.2015.00222

42. Garrison KA, Winstein CJ, Aziz-Zadeh L. The mirror neuron system: a neural substrate for methods in stroke rehabilitation. Neurorehabil Neural Repair. (2010) 24:404-12. doi: 10.1177/1545968309354536

43. Small SL, Buccino G, Solodkin A. The mirror neuron system and treatment of stroke. Dev Psychobiol. (2012) 54:293-310. doi: 10.1002/dev.20504

44. Bartolo A, Cubelli R, Della Sala S. Cognitive approach to the assessment of limb apraxia. Clin Neuropsychol. (2008) 22:27-45. doi: 10.1080/13854040601139310 
45. Smania N, Girardi F, Domenicali C, Lora E, Aglioti S. The rehabilitation of limb apraxia: a study in left-brain-damaged patients. Arch Phys Med Rehabil. (2000) 81:379-88. doi: 10.1053/mr.2000.6921

46. Goldenberg G, Daumuller M, Hagmann S. Assessment and therapy of complex activities of daily living in apraxia. Neuropsychol Rehabil. (2001) 11:147-69. doi: 10.1080/09602010042000204

47. van Heugten CM, Dekker J, Deelman BG, van Dijk AJ, StehmannSaris JC, Kinebanian A. Outcome of strategy training in stroke patients with apraxia: a phase II study. Clin Rehabil. (1998) 12:294-303. doi: 10.1191/026921598674468328

48. Donkervoort M, Dekker J, Stehmann-Saris FC, Deeolman BG. Efficacy of strategy training in left hemisphere stroke patients with apraxia: a randomised clinical trial. Neuropsychol Rehabil. (2001) 11:549-66. doi: 10.1080/09602010143000093

49. Geusgens CA, van Heugten CM, Cooijmans JP, Jolles J, van den Heuvel WJ. Transfer effects of a cognitive strategy training for stroke patients with apraxia. J Clin Exp Neuropsychol. (2007) 29:831-41. doi: 10.1080/13803390601125971

50. Geusgens C, van Heugten C, Donkervoort M, van den Ende E, Jolles J, van den Heuvel W. Transfer of training effects in stroke patients with apraxia: an exploratory study. Neuropsychol Rehabil. (2006) 16:213-29. doi: 10.1080/09602010500172350

51. Bolognini N, Convento S, Banco E, Mattioli F, Tesio L, Vallar G. Improving ideomotor limb apraxia by electrical stimulation of the left posterior parietal cortex. Brain. (2015) 138:428-39. doi: 10.1093/brain/awu343

52. Buccino G. Action observation treatment: a novel tool in neurorehabilitation. Philos Trans $R$ Soc Lond Ser B Biol Sci. (2014) 369:20130185. doi: $10.1098 /$ rstb.2013.0185

53. Oouchida Y, Suzuki E, Aizu N, Takeuchi N, Izumi SI. Applications of observational learning in neurorehabilitation. Int J Phys Med Rehabil. (2013) 1:146. doi: 10.4172/2329-9096.1000146

54. Rothi LJ, Heilman KM. Apraxia, the Neuropsychology of Action. Hove: Psychology Press (1997)

55. Pazzaglia M, Galli G. Loss of agency in apraxia. Front Hum Neurosci. (2014) 8:751. doi: 10.3389/fnhum.2014.00751

56. Badets A, Blandin Y, Wright DL, Shea CH. Error detection processes during observational learning. Res Q Exerc Sport. (2006) 77:177-84. doi: 10.1080/02701367.2006.10599352

57. Badets A, Blandin $\mathrm{Y}$, Shea CH. Intention in motor learning through observation. Q J Exp Psychol. (2006) 59:377-86. doi: 10.1080/02724980443000773

58. Heyes CM, Foster CL. Motor learning by observation: evidence from a serial reaction time task. Q J Exp Psychol. (2002) 55:593-607. doi: 10.1080/02724980143000389

59. Buchanan JJ, Dean NJ. Specificity in practice benefits learning in novice models and variability in demonstration benefits observational practice. Psychol Res. (2010) 74:313-26. doi: 10.1007/s00426-009-0254-y

60. Hecht H, Vogt S, Prinz W. Motor learning enhances perceptual judgment: a case for action-perception transfer. Psychol Res. (2001) 65:3-14. doi: $10.1007 / \mathrm{s} 004260000043$

61. Casile A, Giese MA. Nonvisual motor training influences biological motion perception. Curr Biol. (2006) 16:69-74. doi: 10.1016/j.cub.2005.10.071

62. Rosenkranz K, Williamon A, Rothwell JC. Motorcortical excitability and synaptic plasticity is enhanced in professional musicians. J Neurosci. (2007) 27:5200-6. doi: 10.1523/JNEUROSCI.0836-07.2007

63. Kleim JA, Hogg TM, VandenBerg PM, Cooper NR, Bruneau R, Remple M. Cortical synaptogenesis and motor map reorganization occur during late, but not early, phase of motor skill learning. J Neurosci. (2004) 24:628-33. doi: 10.1523/JNEUROSCI.3440-03.2004

64. Sale P, Franceschini M. Action observation and mirror neuron network: a tool for motor stroke rehabilitation. Eur J Phys Rehabil Med. (2012) 48:313-8.

65. Franceschini M, Ceravolo MG, Agosti M, Cavallini P, Bonassi S, Dall'Armi $\mathrm{V}$, et al. Clinical relevance of action observation in upper-limb stroke rehabilitation: a possible role in recovery of functional dexterity. A randomized clinical trial. Neurorehabil Neural Repair. (2012) 26:456-62. doi: $10.1177 / 1545968311427406$
66. Sale P, Ceravolo MG, Franceschini M. Action observation therapy in the subacute phase promotes dexterity recovery in right-hemisphere stroke patients. Biomed Res Int. (2014) 2014:457538. doi: 10.1155/2014/457538

67. Park HR, Kim JM, Lee MK, Oh DW. Clinical feasibility of action observation training for walking function of patients with post-stroke hemiparesis: a randomized controlled trial. Clin Rehabil. (2014) 28:794-803. doi: 10.1177/0269215514523145

68. Bang DH, Shin WS, Kim SY, Choi JD. The effects of action observational training on walking ability in chronic stroke patients: a doubleblind randomized controlled trial. Clin Rehabil. (2013) 27:1118-25. doi: 10.1177/0269215513501528

69. Kim SS, Kim TH, Lee BH. Effects of action observational training on cerebral hemodynamic changes of stroke survivors: a fTCD study. J Phys Ther Sci. (2014) 26:331-4. doi: 10.1589/jpts.26.331

70. Bonifazi S, Tomaiuolo F, Altoè G, Ceravolo MG, Provinciali L, Marangolo P. Action observation as a useful approach for enhancing recovery of verb production: new evidence from aphasia. Eur J Phys Rehabil Med. (2013) 49:473-81.

71. Marangon M, Priftis K, Fedeli M, Masiero S, Tonin P, Piccione F. Lateralization of motor cortex excitability in stroke patients during action observation: a TMS study. Biomed Res. Int. (2014) 2014:251041. doi: 10.1155/2014/251041

72. Brunner IC, Skouen JS, Ersland L, Gruner R. Plasticity and response to action observation: a longitudinal FMRI study of potential mirror neurons in patients with subacute stroke. Neurorehabil Neural Repair. (2014) 28:874-84. doi: $10.1177 / 1545968314527350$

73. Ertelt D, Binkofski F. Action observation as a tool for neurorehabilitation to moderate motor deficits and aphasia following stroke. Neural Regener Res. (2012) 7:2063-74. doi: 10.3969/j.issn.1673-5374.2012.26.008

74. Ertelt D, Hemmelmann C, Dettmers C, Ziegler A, Binkofski F. Observation and execution of upper-limb movements as a tool for rehabilitation of motor deficits in paretic stroke patients: protocol of a randomized clinical trial. BMC Neurol. (2012) 12:42. doi: 10.1186/1471-2377-12-42

75. Ertelt D, Small S, Solodkin A, Dettmers C, McNamara A, Binkofski $\mathrm{F}$, et al. Action observation has a positive impact on rehabilitation of motor deficits after stroke. Neuroimage. (2007) 36(Suppl. 2):T164-73. doi: 10.1016/j.neuroimage.2007.03.043

76. Franceschini M, Agosti M, Cantagallo A, Sale P, Mancuso M, Buccino G. Mirror neurons: action observation treatment as a tool in stroke rehabilitation. Eur J Phys Rehabil Med. (2010) 46:517-23.

77. Kim E, Kim K. Effect of purposeful action observation on upper extremity function in stroke patients. J Phys Ther Sci. (2015) 27:2867-9. doi: $10.1589 /$ jpts.27.2867

78. Harmsen WJ, Bussmann JB, Selles RW, Hurkmans HL, Ribbers GM. A mirror therapy-based action observation protocol to improve motor learning after stroke. Neurorehabil Neural Repair. (2015) 29:509-16. doi: $10.1177 / 1545968314558598$

79. Dettmers C, Nedelko V, Hassa T, Starrost K, Schoenfeld MA. "Video Therapy": promoting hand function after stroke by action observation training - a pilot randomized controlled trial. Int J Phys Med Rehabil. (2014) 2:189. doi: 10.4172/2329-9096.1000189

80. Zhu M-H, Wang J, Gu X-D, Shi M-F, Zeng M, Wang C-Y, et al. Effect of action observation therapy on daily activities and motor recovery in stroke patients. Int J Nurs Sci. (2015) 2:279-82. doi: 10.1016/j.ijnss.2015.08.006

81. Kim C, Bang D. Action observation training enhances upper extremity function in subacute stroke survivor with moderate impairment: a doubleblind, randomized controlled pilot trial. J Korean Soc Phys Med. (2016) 11:133-40. doi: 10.13066/kspm.2016.11.1.133

82. Kuk EJ, Kim JM, Oh DW, Hwang HJ. Effects of action observation therapy on hand dexterity and EEG-based cortical activation patterns in patients with post-stroke hemiparesis. Top Stroke Rehabil. (2016) 23:318-25. doi: 10.1080/10749357.2016.1157972

83. Fu J, Zeng M, Shen F, Cui Y, Zhu M, Gu X, et al. Effects of action observation therapy on upper extremity function, daily activities and motion evoked potential in cerebral infarction patients. Medicine. (2017) 96:e8080. doi: 10.1097/MD.0000000000008080 
84. Celnik P, Webster B, Glasser DM, Cohen LG. Effects of action observation on physical training after stroke. Stroke. (2008) 39:1814-20. doi: 10.1161/STROKEAHA.107.508184

85. Cowles T, Clark A, Mares K, Peryer G, Stuck R, Pomeroy V. Observationto-imitate plus practice could add little to physical therapy benefits within 31 days of stroke: translational randomized controlled trial. Neurorehabil Neural Repair. (2013) 27:173-82. doi: 10.1177/1545968312452470

86. Lee D, Roh H, Park J, Lee S, Han S. Drinking behavior training for stroke patients using action observation and practice of upper limb function. J Phys Ther Sci. (2013) 25:611-4. doi: 10.1589/jpts.25.611

87. Pelosin E, Bove M, Ruggeri P, Avanzino L, Abbruzzese G. Reduction of bradykinesia of finger movements by a single session of action observation in Parkinson disease. Neurorehabil Neural Repair. (2013) 27:552-60. doi: 10.1177/1545968312471905

88. Buccino G, Gatti R, Giusti MC, Negrotti A, Rossi A, Calzetti S, et al. Action observation treatment improves autonomy in daily activities in Parkinson's disease patients: results from a pilot study. Mov Disord. (2011) 26:1963-4. doi: 10.1002/mds.23745

89. Esculier JF, Vaudrin J, Tremblay LE. Corticomotor excitability in Parkinson's disease during observation, imagery and imitation of action: effects of rehabilitation using wii fit and comparison to healthy controls. J Parkinson's Dis. (2014) 4:67-75. doi: 10.3233/JPD-130212

90. Pelosin E, Avanzino L, Bove M, Stramesi P, Nieuwboer A, Abbruzzese G. Action observation improves freezing of gait in patients with Parkinson's disease. Neurorehabil Neural Repair. (2010) 24:746-52. doi: 10.1177/1545968310368685

91. Castiello U, Ansuini C, Bulgheroni M, Scaravilli T, Nicoletti R. Visuomotor priming effects in Parkinson's disease patients depend on the match between the observed and the executed action. Neuropsychologia. (2009) 47:835-42. doi: 10.1016/j.neuropsychologia.2008.12.016

92. Tremblay F, Leonard G, Tremblay L. Corticomotor facilitation associated with observation and imagery of hand actions is impaired in Parkinson's disease. Exp Brain Res. (2008) 185:249-57. doi: 10.1007/s00221-007-1150-6

93. Sgandurra G, Ferrari A, Cossu G, Guzzetta A, Fogassi L, Cioni G. Randomized trial of observation and execution of upper extremity actions versus action alone in children with unilateral cerebral palsy. Neurorehabil Neural Repair. (2013) 27:808-15. doi: 10.1177/1545968313497101

94. Sgandurra G, Ferrari A, Cossu G, Guzzetta A, Biagi L, Tosetti M, et al. Upper limb children action-observation training (UP-CAT): a randomised controlled trial in hemiplegic cerebral palsy. BMC Neurol. (2011) 11:80. doi: 10.1186/1471-2377-11-80

95. Buccino G, Arisi D, Gough P, Aprile D, Ferri C, Serotti L, et al. Improving upper limb motor functions through action observation treatment: a pilot study in children with cerebral palsy. Dev Med Child Neurol. (2012) 54:822-8. doi: 10.1111/j.1469-8749.2012.04334.x

96. Kim JY, Kim JM, Ko EY. The effect of the action observation physical training on the upper extremity function in children with cerebral palsy. J Exerc Rehabil. (2014) 10:176-83. doi: 10.12965/jer.140114

97. Kim JH, Lee BH. Action observation training for functional activities after stroke: a pilot randomized controlled trial. Neurorehabilitation. (2013) 33:565-74. doi: 10.3233/NRE-130991

98. Celnik P, Stefan K, Hummel F, Duque J, Classen J, Cohen LG. Encoding a motor memory in the older adult by action observation. Neuroimage. (2006) 29:677-84. doi: 10.1016/j.neuroimage.2005.07.039

99. Liepert J, Greiner J, Dettmers C. Motor excitability changes during action observation in stroke patients. J Rehabil Med. (2014) 46:400-5. doi: 10.2340/16501977-1276

100. Fogassi L, Ferrari PF, Gesierich B, Rozzi S, Chersi F, Rizzolatti G. Parietal lobe: from action organization to intention understanding. Science. (2005) 308:662-7. doi: 10.1126/science.1106138

101. Gallese V, Fadiga L, Fogassi L, Rizzolatti G. Action recognition in the premotor cortex. Brain. (1996) 119 (Pt 2):593-609. doi: 10.1093/brain/119.2.593

102. Rizzolatti G, Craighero L. The mirror-neuron system. Ann Rev Neurosci. (2004) 27:169-92. doi: 10.1146/annurev.neuro.27.070203.144230

103. Kilner JM. More than one pathway to action understanding. Trends Cogn Sci. (2011) 15:352-7. doi: 10.1016/j.tics.2011.06.005
104. Hermsdorfer J, Li Y, Randerath J, Roby-Brami A, Goldenberg G. Tool use kinematics across different modes of execution. Implications for action representation and apraxia. Cortex. (2013) 49:184-99. doi: 10.1016/j.cortex.2011.10.010

105. Leiguarda RC, Merello M, Nouzeilles MI, Balej J, Rivero A, Nogués M. Limbkinetic apraxia in corticobasal degeneration: clinical and kinematic features. Mov Disord. (2003) 18:49-59. doi: 10.1002/mds.10303

106. Sirigu A, Cohen L, Duhamel JR, Pillon B, Dubois B, Agid Y. A selective impairment of hand posture for object utilization in apraxia. Cortex. (1995) 31:41-55. doi: 10.1016/S0010-9452(13)80104-9

107. Sirigu A, Duhamel JR, Cohen L, Pillon B, Dubois B, Agid Y. The mental representation of hand movements after parietal cortex damage. Science. (1996) 273:1564-8. doi: 10.1126/science.273. 5281.1564

108. Grezes J, Decety J. Functional anatomy of execution, mental simulation, observation, and verb generation of actions: a meta-analysis. Hum Brain Mapp. (2001) 12:1-19. doi: 10.1002/1097-0193(200101)12:1<1::AID-HBM10>3.0.CO;2-V

109. Grafton ST. Embodied cognition and the simulation of action to understand others. Ann N Y Acad Sci. (2009) 1156:97-117. doi: 10.1111/j.1749-6632.2009.04425.x

110. Iacoboni M, Woods RP, Brass M, Bekkering H, Mazziotta JC, Rizzolatti G. Cortical mechanisms of human imitation. Science. (1999) 286:2526-8. doi: $10.1126 /$ science.286.5449.2526

111. Flanagan JR, Johansson RS. Action plans used in action observation. Nature. (2003) 424:769-71. doi: 10.1038/nature01861

112. Buccino G, Binkofski F, Riggio L. The mirror neuron system and action recognition. Brain Lang. (2004) 89:370-6. doi: 10.1016/S0093-934X(03)00356-0

113. Buxbaum LJ, Shapiro AD, Coslett HB. Critical brain regions for tool-related and imitative actions: a componential analysis. Brain. (2014) 137:1971-85. doi: 10.1093/brain/awu111

114. Goldenberg G, Hermsdorfer J, Glindemann R, Rorden C, Karnath HO. Pantomime of tool use depends on integrity of left inferior frontal cortex. Cereb Cortex. (2007) 17:2769-76. doi: 10.1093/cercor/bhm004

115. Mengotti P, Corradi-Dell'Acqua C, Negri GA, Ukmar M, Pesavento V, Rumiati RI. Selective imitation impairments differentially interact with language processing. Brain. (2013). 136:2602-18. doi: 10.1093/brain/awt194

116. Weiss PH, Ubben SD, Kaesberg S, Kalbe E, Kessler J, Liebig T, et al. Where language meets meaningful action: a combined behavior and lesion analysis of aphasia and apraxia. Brain Struct Funct. (2016) 221:563-76. doi: 10.1007/s00429-014-0925-3

117. Hoeren M, Kümmerer D, Bormann T, Beume L, Ludwig VM, Vry MS, et al. Neural bases of imitation and pantomime in acute stroke patients: distinct streams for praxis. Brain. (2014) 137:2796-810. doi: 10.1093/brain/awu203

118. De Renzi E, Lucchelli F. Ideational apraxia. Brain. (1988) 111(Pt 5):1173-85. doi: 10.1093/brain/111.5.1173

119. Bizzozero I, Costato D, Sala SD, Papagno C, Spinnler H, Venneri A. Upper and lower face apraxia: role of the right hemisphere. Brain. (2000) 123(Pt 11):2213-30. doi: 10.1093/brain/123.11.2213

120. Rothi LJ, Mack L, Heilman KM. Pantomime agnosia. J Neurol Neurosurg Psychiatry. (1986) 49:451-4. doi: 10.1136/jnnp.49.4.451

121. Cubelli R, Marchetti C, Boscolo G, Della Sala S. Cognition in action: testing a model of limb apraxia. Brain Cogn. (2000) 44:144-65. doi: 10.1006/brcg.2000.1226

122. Bartolo A, Cubelli R, Della Sala S, Drei S, Marchetti C. Double dissociation between meaningful and meaningless gesture reproduction in apraxia. Cortex. (2001) 37:696-9. doi: 10.1016/S0010-9452(08)70617-8

123. Negri GA, Rumiati RI, Zadini A, Ukmar M, Mahon BZ, Caramazza A. What is the role of motor simulation in action and object recognition? Evidence from apraxia. Cogn Neuropsychol. (2007) 24:795-816. doi: 10.1080/02643290701707412

124. Aglioti SM, Pazzaglia M. Representing actions through their sound. Exp Brain Res. (2010) 206:141-51. doi: 10.1007/s00221-010-2344-x

125. Mahon BZ, Caramazza A. The orchestration of the sensory-motor systems: clues from neuropsychology. Cogn Neuropsychol. (2005) 22:480-94. doi: $10.1080 / 02643290442000446$ 
126. Buxbaum LJ, Kalenine S. Action knowledge, visuomotor activation, and embodiment in the two action systems. Ann N Y Acad Sci. (2010) 1191:20118. doi: 10.1111/j.1749-6632.2010.05447.x

127. Binkofski F, Buxbaum LJ. Two action systems in the human brain. Brain Lang. (2013) 127:222-9. doi: 10.1016/j.bandl.2012.07.007

128. Pazzaglia M, Zantedeschi M. Plasticity and awareness of bodily distortion. Neural Plast. (2016) 2016:9834340. doi: 10.1155/2016/9834340

129. Buccino G, Molinaro A, Ambrosi C, Arisi D, Mascaro L, Pinardi $\mathrm{C}$, et al. Action observation treatment improves upper limb motor functions in children with cerebral palsy: a combined clinical and brain imaging study. Neural Plast. (2018) 2018:4843985. doi: 10.1155/2018/ 4843985

130. Hanna-Pladdy B, Heilman KM, Foundas AL. Cortical and subcortical contributions to ideomotor apraxia: analysis of task demands and error types. Brain. (2001) 124:2513-27. doi: 10.1093/brain/124.12.2513

131. Moro V, Urgesi C, Pernigo S, Lanteri P, Pazzaglia M, Aglioti SM. The neural basis of body form and body action agnosia. Neuron. (2008) 60:235-46. doi: 10.1016/j.neuron.2008.09.022

132. Halsband U, Schmitt J, Weyers M, Binkofski F, Grützner G, Freund HJ. Recognition and imitation of pantomimed motor acts after unilateral parietal and premotor lesions: a perspective on apraxia. Neuropsychologia. (2001) 39:200-16. doi: 10.1016/S0028-3932(00)00088-9

133. Hickok G. Eight problems for the mirror neuron theory of action understanding in monkeys and humans. J Cogn Neurosci. (2009) 21:1229-43. doi: 10.1162/jocn.2009.21189

134. Fogassi L, Luppino G. Motor functions of the parietal lobe. Curr Opin Neurobiol. (2005) 15:626-31. doi: 10.1016/j.conb.2005.10.015

135. Stefan K, Cohen LG, Duque J, Mazzocchio R, Celnik P, Sawaki L, et al. Formation of a motor memory by action observation. J Neurosci. (2005) 25:9339-46. doi: 10.1523/JNEUROSCI.2282-05.2005

136. Bianchi M, Cosseddu M, Cotelli M, Manenti R, Brambilla M, Rizzetti MC, et al. Left parietal cortex transcranial direct current stimulation enhances gesture processing in corticobasal syndrome. Eur J Neurol. (2015) 22:131722. doi: 10.1111/ene. 12748

137. Baldwin KA, McCoy SL. Making a case for acute ischemic stroke. J Pharm Pract. (2010) 23:387-97. doi: 10.1177/0897190010372325

138. Ferro JM, Martins IP, Mariano G, Caldas AC. CT scan correlates of gesture recognition. J Neurol Neurosurg Psychiatry. (1983) 46:943-52. doi: 10.1136/jnnp.46.10.943

139. Catmur C, Gillmeister H, Bird G, Liepelt R, Brass M, Heyes C. Through the looking glass: counter-mirror activation following incompatible sensorimotor learning. Eur J Neurosci. (2008) 28:1208-15. doi: 10.1111/j.1460-9568.2008.06419.x

140. Gazzola V, Rizzolatti G, Wicker B, Keysers C. The anthropomorphic brain: the mirror neuron system responds to human and robotic actions. Neuroimage. (2007) 35:1674-84. doi: 10.1016/j.neuroimage.2007.02.003

141. Mattar AA, Gribble PL. Motor learning by observing. Neuron. (2005) 46:153-60. doi: 10.1016/j.neuron.2005.02.009

142. Buccino G, Solodkin A, Small SL. Functions of the mirror neuron system: implications for neurorehabilitation. Cogn Behav Neurol. (2006) 19:55-63. doi: 10.1097/00146965-200603000-00007

143. Dinstein I, Gardner JL, Jazayeri M, Heeger DJ. Executed and observed movements have different distributed representations in human aIPS. $J$ Neurosci. (2008) 28:11231-9. doi: 10.1523/JNEUROSCI.3585-08.2008

144. Mahon BZ. Action recognition: is it a motor process? Curr Biol. (2008) 18:R1068-9. doi: 10.1016/j.cub.2008.10.001
145. Tkach D, Reimer J, Hatsopoulos NG. Congruent activity during action and action observation in motor cortex. J Neurosci. (2007) 27:13241-50. doi: 10.1523/JNEUROSCI.2895-07.2007

146. Brown LE, Wilson ET, Gribble PL. Repetitive transcranial magnetic stimulation to the primary motor cortex interferes with motor learning by observing. J Cogn Neurosci. (2009) 21:1013-22. doi: 10.1162/jocn.2009.21079

147. Pazzaglia M, Galli G, Lewis JW, Scivoletto G, Giannini AM, Molinari M. Embodying functionally relevant action sounds in patients with spinal cord injury. Sci Rep. (2018) 8:15641. doi: 10.1038/s41598-018-34133-z

148. Pazzaglia M. Body and odors: not just molecules, after all. Curr Dir Psychol Sci. (2015) 24:329-33. doi: 10.1177/0963721415575329

149. Aglioti SM, Pazzaglia M. Sounds and scents in (social) action. Trends Cogn Sci. (2011) 15:47-55. doi: 10.1016/j.tics.2010.12.003

150. Pazzaglia M, Galli G, Lucci G, Scivoletto G, Molinari M, Haggard P. Phantom limb sensations in the ear of a patient with a brachial plexus lesion. Cortex. (2018). doi: 10.1016/j.cortex.2018.08.020. [Epub ahead of print].

151. Pazzaglia M, Haggard P, Scivoletto G, Molinari M, Lenggenhager B. Pain and somatic sensation are transiently normalized by illusory body ownership in a patient with spinal cord injury. Restor Neurol Neurosci. (2016) 34:603-13. doi: $10.3233 / \mathrm{RNN}-150611$

152. Costantini M, Bueti D, Pazzaglia M, Aglioti SM. Temporal dynamics of visuo-tactile extinction within and between hemispaces. Neuropsychology. (2007) 21:242-50. doi: 10.1037/0894-4105.21.2.242

153. Goldenberg G, Hentze S, Hermsdorfer J. The effect of tactile feedback on pantomime of tool use in apraxia. Neurology. (2004) 63:1863-7. doi: 10.1212/01.WNL.0000144283.38174.07

154. Pazzaglia M, Leemhuis E, Giannini AM, Haggard P. The Homuncular Jigsaw: investigations of phantom limb and body awareness following brachial plexus block or avulsion. J Clin Med. (2019) 8:E182. doi: 10.3390/jcm8020182

155. Pazzaglia M, Scivoletto G, Giannini AM, Leemhuis E. My hand in my ear: a phantom limb re-induced by the illusion of body ownership in a patient with a brachial plexus lesion. Psychol Res. (2019) 83:196-204. doi: 10.1007/s00426-018-1121-5

156. Galli G, Pazzaglia M. Commentary on: "the body social: an enactive approach to the self". A tool for merging bodily and social self in immobile individuals. Front Psychol. 6:305. doi: 10.3389/fpsyg.2015.00305

157. Lucci G, Pazzaglia M. Towards multiple interactions of inner and outer sensations in corporeal awareness. Front Hum Neurosci. (2015) 9:163. doi: 10.3389/fnhum.2015.00163

158. Cramer SC, Sur M, Dobkin BH, O’Brien C, Sanger TD, Trojanowski JQ, et al. Harnessing neuroplasticity for clinical applications. Brain. (2011) 134:1591-609. doi: 10.1093/brain/awr039

159. Law LLF, Fong KNK, Li RKF. Multisensory stimulation to promote upper extremity motor recovery in stroke: a pilot study. Brit J Occup Ther. (2018) 81:641-8. doi: 10.1177/0308022618770141

Conflict of Interest Statement: The authors declare that the research was conducted in the absence of any commercial or financial relationships that could be construed as a potential conflict of interest.

Copyright (C) 2019 Pazzaglia and Galli. This is an open-access article distributed under the terms of the Creative Commons Attribution License (CC BY). The use, distribution or reproduction in other forums is permitted, provided the original author(s) and the copyright owner(s) are credited and that the original publication in this journal is cited, in accordance with accepted academic practice. No use, distribution or reproduction is permitted which does not comply with these terms. 